\title{
Study on Prevalence of Bovine Cystcercosis and Public Health Importance of Taeniosis at the Nekemte Municipal Abattoir, Nekemte, Western Oromia
}

\author{
Wabi Emiru* and Girmay hiluf \\ School of Veterinary Medicine, Mekelle University, Ethiopia
}

Submission: December 18, 2018; Published: January 17, 2019

*Corresponding author: Wabi Emiru, School of Veterinary Medicine, Mekelle University, P.O.Box, 3006, mekelle, Ethiopia

\begin{abstract}
Bovine cysticercosis is an infection of cattle caused by the larval stage, Cysticercus bovis, of the human intestinal cestode, Taenia saginata. It is an infection that has public health significances as a result of eating raw or undercooked beef meat results taeniasis in humans. A cross sectional study was conducted during November 2016 up to April 2017 to estimate prevalence of bovine cystcercosis, assess of the associated risk factor and public health importance of Taeniosis at the Nekemte Municipal abattoir, Nekemte Town. Routine meat inspection method and questionnaire survey on conveniently selected respondents in the study areas were used. Out of 410 carcasses examined during the study period in Nekemte municipality abattoirs $2.68 \%(11 / 410)$ were infected with $C$. bovis.

The result revealed that, the prevalence of Cysticercus bovis in slaughtered cattle $2.68 \%$ and the affected organs were masseter, tongue, triceps and tongue, masseter and triceps with an infection rate of $0.5 \%, 1.0 \%, 1.0 \%$ and $0.25 \%$ respectively. Cysts were found in triceps (36.4\%), tongue $(36.4 \%)$ and masseter $(18.2 \%)$ and tongue, masseter, triceps $(9.1 \%)$. Out of the cysts $45.5 \%(5 / 11)$ were viable, while $55.5 \%(6 / 11)$ were non-viable. Even though there is no statistically Significant difference among different age's groups, sex and breed animals, the prevalence was roughly varied. The questionnaire survey revealed that T. saginata/taeniosis is a wide spread problem in these Nekemte towns. Out of 103 respondents $13.6 \%$ (14/103) had contracted T. saginata. Age, sex, religion, occupation, education level, raw meat consumption, knowledge about the disease and presence or absence of the latrine was found as potential risk factors of taeniosis. In conclusion, C. bovis is prevalent and is one of the major parasitic diseases that causes carcass condemnation of slaughtered animals and poses serious financial lose in the socio-economy of the study area. Therefore, public health awareness should be created on improving personal and environmental hygiene for breaking the life cycle of the disease.
\end{abstract}

Keywords: Cysticercosis; Taeniasis; Nekemte; Prevalence; Public health

Abbrevations: C. bovis: Cystcercus Bovis; CSA: Central Statistical Agency; EURO: Ethiopian Agricultural Research Organization; OIE: Office of International des Epizootes; p-value: Pearson's Value; SPSS: Statistical Package for Social Science; T. Saginata: Teania Saginata; WHO: World Health Organization

\section{Introduction}

The metacestodes of Taenia species are the cause of cysticercosis in various farmed and wild animals and in humans. Bovine cysticercosis is a muscular infection of cattle and is caused by larvae of the human intestinal cestode Taenia saginata. Infection of human by Taenia saginata occurs through ingestion of raw or undercooked meat containing cysticercus bovis. While, infection of cattle with cysticercus bovis occurs through ingestion of Taenia saginata eggs [1]. Its life cycle is entirely dependent on the link between man and cattle so that any break in this links can result in the total elimination of the parasite. The transmission of parasite occurs most commonly in environments characterized by poor sanitation, primitive livestock husbandry practices and inadequate meat inspection, management and control policies [2]. Tapeworm infections have been recorded in history from $1500 \mathrm{BC}$ and have been recognized as one of the earliest human parasites [3].

Taenia saginata of humans causes bovine cysticercosis, which occurs virtually world-wide, but particularly in Africa, Latin America, Caucasian and South/Central Asia and eastern Mediterranean countries. The infection occurs in many countries in Europe and sporadically in the United States of America (USA), Canada, Australia and New Zealand [4]. Recently, the World Health Organization (WHO) included cysticercosis as part of the Neglected Zoonosis subgroup for its 2008-2015 strategic plans for the control of neglected tropical diseases [5]. This disease causes considerable livestock-associated financial 
losses and represents a significant food safety problem. The epidemiology of bovine cystcercosis/human taeniasis varies from one area to another, so control measures appropriate in one area is not necessarily of value in another. Based on routine carcass inspection, the infection rate of bovine cysticercosis is often around $30-60 \%$ in developing countries although the real prevalence could be considerably high [6].

In Ethiopia several authors have been reported the prevalence of taeniasis and cysticercosis with in a wide range of $2.5 \%$ to $89.41 \%$ and $3.11 \%$ to $27.6 \%$, respectively [7-9]. According to these reports, a prevalence of $2.0 \%$ in Gondar by Ezeddin \& Tewodros [10], 2.98\% in Nekemte by Abbunna [11], $5.6 \%$ in Bishoftu by Emiru 7.23\% in Mekelle by Getachew \& Ashwain [12], 19.5\% in Bahir Dar by Mulugeta [13] and 3.2\% in different agro climatic zones was recorded by Tembo [6]. The cultural habit of eating raw meat in the form of "Kurt" meat cubes and "Kitffo" minced meat in Ethiopia, has favored the spread of this disease $[14,15]$. Live cattle having C. bovis show no symptoms and the presence of the cysts in carcasses is observed visually during the routine meat inspection by making different incisions into muscles and organs; however, the adult tape worm in man produced diarrhea, hunger pain, abdominal discomfort, constipation and nausea [16].

Taenia has a debilitating effect on people who live on protein deficient diets those suffering from iron deficiency infected by hookworm, some patients lose their appetite and thus lose weight. Sometimes, the gravid proglottids migrate to different organs such as the appendix, pancreatic duct, nasopharyngeal pathways and bile ducts producing obstruction and inflammation of the affected organs [17]. Economic loss is high due to condemnation heavily infected meat, restriction of exports and treatment costs in human for Taeniasis [18]. Taeniasis and Cysticercosis causes significant economic impact in many parts of the world, particularly in developing countries by hindering the export of live animal and animal products. The nation's domestic meat consumption of about $45 \%$ comes from cattle, which generates export income mainly from the sale of live animals [19].

On the other hand, the contributions of Cysticercus bovis to organ condemnation in slaughtered cattle at different abattoir have been reported $[20,21]$. It is a great problem in developing country like Ethiopia due to the cultural habit of eating raw meat in form of "Kurt" and "Kitffo" as routine dish and during holidays has promoted the spread of human taeniasis in Ethiopia [22]. The above-mentioned problems allow the parasite to continue its life cycle till to date and in the coming future $[23,24]$. The estimation of the cyst viability is important for decision making, planning of development and implementation of control strategies. Despite the presence of high prevalence of the disease in other areas only a limited study has so far done in the current study area. Hence, no adequate information is available regarding epidemiology and public health significance of the diseases.

Therefore, the Objective of this study were: a. To estimate the prevalence of cysticercosis in Nekemte Municipal Abattoirs,

b. To assess the community perception about meat-borne zoonosis using risk factors an indicator.

\section{Materials and Methods}

\section{Study Area}

The study was conducted in eastern Wollega zone, western parts of Ethiopia at Nekemte municipal abattoir. Nekemte town is in Oromiya regional state of Ethiopia, which about $331 \mathrm{~km}$ far from Addis Ababa. It is located at altitudinal ranges from 2100 to 2250 meters above sea level and geographically it is located $09^{\circ} 04^{\prime} 957 \mathrm{~N}$ latitude and $36^{\circ} 32^{\prime} 928 \mathrm{E}$ longitude. It has different agro-ecological areas namely sub moist, sub moist cool and sub dega. The annual rain falls ranges from 1560 to $2200 \mathrm{~mm}$ and the minimum and maximum temperature ranges from 14 to $26^{\circ} \mathrm{C}$. Its maximum rainfall occurs from May up to September. The livestock population of the area comprises of 74574 of cattle; 11110 sheep; 1007 goats; 5074 equines and 36186 heads of chickens. The abattoir an average of 30 cattle every day and 9,000 heads of cattle are slaughtered at the abattoir annually.

\section{Study Population}

Study population was cattle presented to Nekemte municipal abattoir for slaughtering. The study population consists of 410 cattle at different ages, sex and breeds categories in the study area. The sources of animals for the study were from districts around the town (Bandira, Gute, Uke, Arjo, Arjo Guddatu, Diga, Gaba Jimata, Sasiga, Wayu Tuka, Getema, and Nekemte). The slaughtered animals in the abattoir were inclusive of the two sexes (males and females).

\section{Study Design}

A cross sectional study was conducted from November 2016-April 2017 to determine the prevalence and public health significance of cystcercosis in the study area.

\section{Sample Size and Sampling Methods}

Sampling was conducted using random sampling method. The sample size was determined using a method recommended by Thrusfield [25] with 95\% confidence level, 5\% desired absolute precision and expected prevalence

$$
N=\frac{1.962 * p \exp (1-p \exp )}{d_{2}}
$$

Where $n=$ required sample size

Pexp= expected prevalence

$\mathrm{d} 2$ =desired absolute precision

Previous study made in Nekemte abattoir showed the prevalence of $C$. bovis in cattle to be $2.98 \%$ (Abunna et al., 2011). Therefore, by using this $2.98 \%$ expected prevalence, at 
a confidence interval of $95 \%$ and required absolute precision of $5 \%$, accordingly, a total of 45 cattle was supposed to be sampled. However, to raise the level of accuracy of prevalence determination, the sample size was increased to 410 in the current study.

\section{Study Methodology}

Active Abattoir Survey: A cross sectional study was conducted during detail meat inspection on randomly selected 410 cattle slaughtered at Nekemte municipal abattoir. Before slaughtering and inspecting the animals, ante mortem inspection was carried out and the ID number of each animal was recorded. Ante mortem examination on individual animals was done for the records of age, sex, breed and their place of origin. During post mortem inspection, visualization and palpation of the organs followed by incision of organs was made to examine for the presence of $C$. bovis, according to the guideline by Thrusfield [25] for masseter muscle, deep linear incision were made parallel to the mandible; the heart was incised from base to apex to open the pericardium and incise also made in the cardiac muscle for detail examination. Deep, adjacent and parallel incisions were made above the point elbow in the shoulder muscle. Examination of the kidney, liver, and the lung was also conducted accordingly.

Cystic Viability Test: All positive samples were transported to the parasitology laboratory in Wollega University, School of Veterinary Medicine for confirmation of cyst viability. The cysts were incubated in ox bile at $37{ }^{\circ} \mathrm{C}$ for $1-2 \mathrm{hrs}$. using $40 \%$ ox bile solution diluted in normal saline for $1-2 \mathrm{hrs}$. After this, the scolex was examined under microscope by pressing between two glass slides. The cysts were regarded as viable if the scolex envaginates during the incubation period at the same time the scolex was checked whether it is T.saginata metacestode or other based on the size of cysticercus, absence of hook on the rostellum of the envaginated cyst [26].

Questionnaire Surveys on Taeniasis: Identification of respondents for questionnaire survey was based on random selection of volunteers from Nekemte town. The selection was based on different age, sex, and working conditions. Accordingly, 103 volunteer individuals were selected and interviewed. Questionnaire survey on the disease occurrence and risk factors was administered on those 103 volunteer respondents from whom pre-informed consents were obtained. The potential risk factors of taeniasis such as habit of raw meat consumption, age, sex, religion, occupation, educational levels, presence and usage of sanitary facilities especially toilet and knowledge of $T$. saginata were assessed. Specific questions regarding medical history related to traditional and modern taeniacidal drugs use, impacts of taeniasis and possible options were included in the questionnaire to estimate the risk factors association with taeniasis.

\section{Data Management and Analysis}

The data was checked, coded and entered in to Microsoft excel work sheet and analyzed using SPSS software. Descriptive statistics like percentage was used to express prevalence, while chi-square $\left(\chi^{2}\right)$ test was used to compare the association of cysticercosis with different risk factors. In all the cases, 95\% confidence level and 0.05 absolute precision errors were considered. A p-value $<0.05$ was used to verify statistically significance difference.

\section{Result}

\section{Prevalence}

During the period of this study, ante mortem and postmortem examinations were performed on 410 cattle in Nekemte Municipal abattoir. For the ante mortem examination, general condition of the animal was observed by visual inspection and age, breed as well as the origin of the animal were recorded. Out of the total 410 cattle examined, $11(2.68 \%)$ were found to be positive for C. bovis.

\section{Occurrence of $\boldsymbol{C}$. bovis in different organs of cattle}

Table 1: Prevalence of $C$. bovis in different organs.

\begin{tabular}{|c|c|c|}
\hline $\begin{array}{c}\text { Distribution of Cyst Per } \\
\text { Organ }\end{array}$ & Number of \\
Organs Inspected & 4 & $\begin{array}{c}\text { Prevalence } \\
\text { (\%) }\end{array}$ \\
\hline Tongue & 2 & 1.0 \\
\hline Masseter & 4 & 0.5 \\
\hline Triceps & 0 & 1.0 \\
\hline Heart & 0 & 0.0 \\
\hline Diaphragm & 1 & 0.0 \\
\hline Tongue, Masseter and Triceps & 11 & 0.25 \\
\hline Total & & 2.68 \\
\hline
\end{tabular}

Table 2: Distribution of cysts in different organ of the affected animals.

\begin{tabular}{|c|c|c|}
\hline Infected organ/muscle & No of infected cattle & Proportions (\%) \\
\hline Tongue & 4 & 36.4 \\
\hline Masseter & 2 & 18.2 \\
\hline Triceps & 4 & 36.4 \\
\hline Heart & 0 & 0 \\
\hline Diaphragm & 0 & 0 \\
\hline $\begin{array}{c}\text { Tongue + masseter + } \\
\text { triceps }\end{array}$ & 1 & 9.1 \\
\hline Total & 11 & 100 \\
\hline
\end{tabular}

Shoulder muscle (triceps), tongue, masseter muscle, heart and diaphragm were inspected. Among the eleven (11) cattle that were confirmed positive, $4(1.0 \%)$ were from shoulder muscle, $4(1.0 \%)$ from tongue and $2(0.5 \%)$ were from masseter muscle and $1(0.25 \%)$ from shoulder, tongue and masseter (Table 1). Both single and multiple infected organ were recorded. Out of the total cattle 11 harboring of $C$. bovis 10 (91.0\%) involved single infected organ whereas the remaining $1(9.1 \%)$ infected animals had multiple organ involvement (Table 2) Similarly, this study significantly showed that from the observed Adult aged cattle, the most affected organ was shoulder muscle and tongue, followed by the masseter muscle. 


\section{Journal of Dairy \& Veterinary Sciences}

\section{Questionnaire Surveys on Taeniasis}

Out of the total 103 interviewed volunteer respondents of Nekemte town who were participated on different working environments, $13.5 \%(14 / 103)$ had contracted T. saginata. In the present study, of the 103 respondents, 85 individuals disclosed the habit of raw and partial cooked meat consumption and none of the females responded yes for Taeniasis. The chi-

Table 3: Distribution of cysts in different organ of the affected animals.

\begin{tabular}{|c|c|c|c|}
\hline Variable & Category & Frequency & Percentage (\%) \\
\hline \multirow{3}{*}{ Age } & Below 18 & 24 & 23.3 \\
\hline & $18-30$ & 34 & 33 \\
\hline & Above 30 & 45 & 43.7 \\
\hline \multirow{2}{*}{ Sex } & Male & 88 & 85.4 \\
\hline & Female & 15 & 14.6 \\
\hline \multirow{2}{*}{ Religion } & Christian & 92 & 89.3 \\
\hline & Muslim & 11 & 10.7 \\
\hline \multirow{4}{*}{ Occupation } & Students & 29 & 28.2 \\
\hline & Farmers & 9 & 8.7 \\
\hline & G/employment & 24 & 23.3 \\
\hline & Own jobs & 41 & 39.8 \\
\hline \multirow{4}{*}{ Level of education } & Illiterate & 7 & 6.8 \\
\hline & Elementary school & 30 & 29.1 \\
\hline & High school & 41 & 39.8 \\
\hline & Others & 25 & 24.3 \\
\hline \multirow{5}{*}{ Meat consumption } & Raw meat & 3 & 2.9 \\
\hline & Raw and partial cooked & 86 & 83.1 \\
\hline & Only partial cooked & 6 & 5.8 \\
\hline & Only properly cooked & 8 & 7.8 \\
\hline & More than one & 10 & 9.7 \\
\hline
\end{tabular}

Table 4: Chi-square analysis of risk factors with the occurrence human Taeniasis.

\begin{tabular}{|c|c|c|c|c|c|}
\hline \multirow[t]{2}{*}{ Predictor Variables } & \multirow[t]{2}{*}{ Category } & \multicolumn{2}{|c|}{ Taenia Infection } & \multirow[t]{2}{*}{$\mathbf{X} 2$} & \multirow[t]{2}{*}{ P-value } \\
\hline & & Not infected & Infected & & \\
\hline \multirow{2}{*}{ Sex } & Male & $74(83.1 \%)$ & $14(100 \%)$ & & \\
\hline & Female & $15(16.9 \%)$ & $0(0 \%)$ & 2.762 & 0.097 \\
\hline \multirow{3}{*}{ Age } & Below 18 & $24(27 \%)$ & $0(0 \%)$ & & \\
\hline & $18-30$ & $30(33.7 \%)$ & $4(28.6 \%)$ & 6.726 & 0.035 \\
\hline & Above 30 & $35(39.3 \%)$ & $10(71.4 \%)$ & & \\
\hline \multirow{2}{*}{ Religion } & Christian & $79(88.8 \%)$ & $13(92.97 \%)$ & & \\
\hline & Muslim & $10(11.2 \%)$ & $1(7.1 \%)$ & 0.212 & 0.645 \\
\hline Level of & Illiterate & $4(4.5 \%)$ & $3(21.4 \%$ & & \\
\hline \multirow[t]{3}{*}{ Education } & Elementary school & $23(5.8 \%)$ & $7(50 \%)$ & & \\
\hline & High school & $39(43.8 \%)$ & $2(14.3 \%)$ & 10.845 & 0.013 \\
\hline & Others & $23(25.8 \%)$ & $2(14.3 \%)$ & & \\
\hline \multirow{4}{*}{ Occupation } & Students & $28(31.5 \%)$ & $1(7.1 \%)$ & & \\
\hline & Farmers & $6(6.7 \%)$ & $3(21.4 \%)$ & & \\
\hline & G/employment & $23(25.8 \%)$ & $1(7.1 \%)$ & 9.782 & 0.021 \\
\hline & Own jobs & $32(36.0 \%)$ & $9(64.3 \%)$ & & \\
\hline
\end{tabular}

squared analysis of risk factors associated with the occurrence of human taeniasis revealed a significant difference $(\mathrm{p}<0.05)$ for the age group, sex, occupation, level of education and raw meat consumption habit of respondents. Regarding the age, occupation, level of education and meat consumptions, higher alence of infection was recorded in individuals who are older age (above 30), Own jobs, elementary schools and raw and partial cooked meat consumers respectively (Tables $3 \& 4$ ). 
Journal of Dairy \& Veterinary Sciences

\begin{tabular}{|c|c|c|c|c|c|}
\hline \multirow{5}{*}{ Meat consumption } & Raw meat & $1(1.1 \%)$ & $2(14.3 \%)$ & & \\
\hline & Raw and partial cooked & $69(77.5 \%$ & $7(50.0 \%)$ & & \\
\hline & Only partial cooked & $5(5.6 \%)$ & $1(7.1 \%)$ & & \\
\hline & Only properly cooked & $8(9.0 \%)$ & $0(0.0 \%)$ & 15.682 & 0.003 \\
\hline & More than one & $6(6.7 \%)$ & $4(28.6 \%)$ & & \\
\hline
\end{tabular}

\section{Discussion}

Among the 410 carcasses of cattle inspected in Nekemte municipal abattoir from November 2016 to April 2017, 11 carcasses were found to harbor cysts of $C$. bovis with an overall prevalence of $2.68 \%$ in various organs. The results of the current study agreed with the findings of $2.0 \%$ in Gondar by $[10,27,28]$ in Jimma municipal abattoir with prevalence of $2.93 \%$ and $3.6 \%$, respectively, of [6] 3.2\% in central Ethiopia, [11] 2.98\% in Nekemte and [29] 3.6\% in Addis Ababa abattoir. However, in this study finding was lower than the prevalence reported by previous authors in different parts of Ethiopia such as $18.49 \%$ in north western Ethiopia by [30]; 7.5\% in Addis Ababa Abattoir by [31]; 43\% in Hawassa by Abunna [9]; 19.5\% in Bahir Dar by Mulugeta [13] and 17.5\%, in East Shoa.

This might be since the incidence of $C$. bovis varies from country to country and reflects the expertise of meat inspectors. Moreover, in the routine inspection of cattle carcasses, there is practical limitation to the number and degree of incisions permissible, for gross mutilation lowers the marketability of the carcass, as a result many infestations remain undetected. The flooding of pastures, use of sewage effluent for pasture irrigation without adequate treatment, free access of cattle to surface water, proximity of waste water effluent, keeping the animals indoor, farm sanitation, farmer's education about the disease and also attributed to the change in culture of raw meat consumption, awareness in using latrine and low contamination from where animals were bought are the other factors that make the difference in prevalence percent of bovine cysticercosis.

Taeniasis /Cysticercosis occur most commonly in the environments characterized by poor sanitation, primitive livestock husbandry practice and inadequate meat inspection and control. Bovine cysticercosis usually does not cause much morbidity or mortality among cattle, but it does cause serious economic problems in the endemic areas due to the condemnation of meat or down grading of carcasses contributing to constraint in food security and safety [32], It appears several risk factors, such as activity of the muscles, age, breed and the geographical area concerned and parasite strain determine largely the predilection sites in cattle [18]. C. bovis was recorded at various sites on the infected carcasses. They were present in tongues of $1.0 \%$, triceps muscles of $1.0 \%$, masseter muscles of $0.5 \%$ and tongue, masseter and triceps of $0.25 \%$ cattle. This finding agreed with the report of in Eastern Shoa, in Hawassa by Abunna [33] and in Hawassa by Mesfin and Nuradddis in konbolcha by Jemal \& Haileleul [34] who reported that the tongue and triceps was the most frequently affected organ. Cysticercus bovis are commonly found in muscles of mastication, particularly masseter muscles, shoulder muscles, heart, tongue, diaphragm and occasionally in fat, liver, lungs and lymph nodes and all the parts of carcasses were equally important as predilection sites for cysticerci and could be equally used during routine meat inspection at slaughter houses except for rumen, fat layers, spleen and skin [32].

Of the total cystcercus collected and examined in different organs $5(45.5 \%)$ viable and the remaining $6(55.0 \%)$ were degenerated. The highest number of viable cysts $(36.4 \%)$ was found in Tongue and Triceps followed by Masseter (18.2\%) and three of them were $(9.1 \%)$. The proportion of Triceps affected with $C$. bovis was $36.6 \%$ which agrees with the reports of [8] $32 \%$, [35,36] $46 \%$. However, the present finding is greater than the findings of $27 \%$ in Wolaita Soddo by Regassa [30] who recoded shoulder cyst proportion. This variation might be due to the ability of the meat inspector to identify the cases, sample size, method of meat inspection and number of cuts.

Based on the questionnaire survey to the volunteer respondents the prevalence of $T$. saginata recorded in this study was $13.5 \%$ illustrated the significance of taeniasis in the population of Nekemte town and not agrees with the findings of others, 64.2\% Hawassa by Abunna [33], 51.1\% Wolaita by Regassa [30] 79.5\% in Eastern Shoa by Hailu [8], 69.2\% in North Gondar by Dawit [7].This differences is due to the reason behind of awareness of the people about the cause of taeniasis, proper activity of meat inspector and decreasing culture of the consumption of raw meat.

\section{Conclusion and Recommendations}

There are several factors associated with wide distribution of C. bovis: raw and under cooked beef consumption, field defecation and poor waste disposal and sewage treatment system, low level of public awareness and presence of backyard slaughtering practices. In present study, both abattoir and questionnaires showed that T.saginata was an important parasitic cattle disease and in terms of its public health implications in the study area because Bovine cysticercosis has its own public health significance. After ingestion of cyst by human beings develop into adult parasite, T. saginata, leading to anorexia, loss of weight, abdominal pain, digestive disturbances and insomnia. Sometimes the mobile gravid segments of adult parasite may make their way to unusual sites such as the appendix, uterus or biliary tract and may cause serious disorders.

Therefore, based on the above conclusions the following recommendations are forwarded

a. Awareness creation to the society as to reduce and ultimately avoid consumption of raw meat. 
b. Awareness creation to improving the general animal health management system.

c. Awareness creation to meat inspection, appropriate treatment of infected people and the use of latrine must be encouraged to tackle and reduce the problem in the areas.

d. Further well-organized public education in each sector and designing community-based control strategies.

e. Public health awareness should be created through public media on improving personal and environmental hygiene for breaking the life cycle of the disease.

f. In general, veterinarians and medical professionals ought to work in collaboration for the control of this disease.

\section{Acknowledgement}

Above all, I would like to praise the Almighty GOD for his Merciful help and guidance throughout my life and in all ups and downs of my school and university life and in bringing me this far. I would like to extend my heartfelt gratitude to my advisors Mr. Girmay Hiluf for their valuable support, suggestion provisions of materials guidance during my work time and correction of this paper. Finally, my heartfelt thanks go to my families for their financial support, advice, and encouragement throughout my academic year and I have special thanks for my friend Takuma Fatane for her special support during this study.

\section{References}

1. Dupuy C, Morlot C, Gilot-Fromont E, Mas M, Grandmontagne C, et al. (2014) Prevalence of Taenia saginata cysticercosis in French cattle. Veterinary Parasitology 16(1-2): 65-72.

2. Phiri I, Ngowi H, Afonso S, Matenga E, Boa M, et al. (2003) The Emergence of Taenia Solium Cysticercosis in East and Southern Africa as a Serious Agricultural Problem and Public Health Risk. Acta Tropica. 87: 13-23.

3. Urquhart G, Armour J, Duncan A, Dunn F, Jennings A (2013) Veterinary Parasitology. ( $8^{\text {th }}$ edn), Black Well Science, London, pp: 120-137.

4. OIE (2014) Terrestrial manual. Cysticercosis, pp. 452-456.

5. WHO (2013) Taeniasis/cysticercosis. WHO Fact sheet $\mathrm{N}^{\circ} 376$.

6. Tembo A (2001) Epidemiology of Taenia saginata taeniasis and cysticercosis in three selected agro- climatic zones in central Ethiopia. M.Sc thesis, Faculty of Veterinary Medicine, Addis Ababa University, Ethiopia.

7. Dawit S (2004) Epidemiology of T. saginata Taeniasis and Cysticercosis in North Gonder Zone, North Western Ethiopia. DVM Thesis, FVM, AAU, Debre Zeit, Ethiopia.

8. Hailu D (2005) Prevalence and risk factors for T. Saginata cysticercosis in three selected areas of eastern Shoa. M.Sc Thesis, Addis Ababa University, Faculty of Veterinary Medicine, Debra Zeit, Ethiopia.

9. Abunna F, Tilahun G, Megersa B, Regassa A, Kumsa B (2008) Bovine cysticercosis in cattle slaughtered at Hawassa municipal abattoir, Ethiopia. Zoonotic. Public. Health 55(2): 82-88.

10. Ezeddin A, Tewodros A (2016) Epidemiological Studies on Cysticercus bovis at Gondar ELFORA Abattoir, North West of Ethiopia. Journal of veterinary science and technology 7:5

11. Abunna F, Ayala D, Regassa A, Megersa B, Debela E (2011) Major Metacestodes in Cattle Slaughtered at Nekemte Municipal Abattoir,
Western Ethiopia: Prevalence, Cyst Viability, Organ Distribution and Socioeconomic Implications) Biomirror, p. 1-7.

12. Getachew A, Ashwani K (2013) Cysticercosis in cattle and its public health implications in Mekelle City and surrounding areas, Ethiopia. College of Veterinary Medicine, Mekelle University, Ethiopian. Veterinary Journal, 17(1): 31-40.

13. Mulugeta A (1997) Bovine cysticercosis: prevalence, economic and public health importance at Bahir Dar municipal abattoir. DVM thesis. Addis Ababa University, Faculty of Veterinary Medicine, Debra Zeit, Ethiopia.

14. Fralova A (2014) Taeniosis. In: Zoonotic control. Lysenko A UNEP Publication, Moscow, Russia, pp: 192-239.

15. Abunna F (2006) Study on the Prevalence of Bovine Cysticercosis in Hawassa Municipal FVM, AAU, Debre Zeit, Ethiopia.

16. Mesfin B, Nuradddis I (2012) Prevalence of Cysticercus Bovis in Hawassa Municipal Abattoir and its Public Health Implication. American- Eurasian Journal of Scientific Research. 7(6): 238-245.

17. Ortega Y (2006) Foodborne parasites. New York: Springer, pp. 207210.

18. Scandrett B, Parker S, Forbes L, Gajadhar A, Dekumyoy P, et al. (2009) Distribution of Taenia Saginata Cysticerci in Tissues of Experimentally Infected Cattle. Veterinary Parasitology. 164: 223-231.

19. EARO (Ethiopian Agricultural Research Organization) (2015) Beef Research Strategy. Animal Science Directorate. Addis Ababa, Ethiopia, pp: 241-243.

20. Fekadu D (2015) A study on cestodes and metacestode of sheep in Sheno agricultural Research (SHARC), North Shoa. DVM Thesis, Faculty of Veterinary Medicine, Addis Ababa University, Debra Zeit, Ethiopia.

21. Yimam M (2003) Major causes of organ condemnation in ruminants slaughtered at Gondar abattoir, Northwest Ethiopia. DVM thesis, Addis Ababa University, Faculty of Veterinary Medicine, Debre Zeit, Ethiopia.

22. Gebra-Emanuael T (1997) Food Hygiene - Principles and methods of food borne disease control with special Reference to Ethiopia. Faculty of Medicine, Department of Community Health, Addis Ababa University, Ethiopia.

23. Eckert J (1996) Workshop summary: Food safety: meat-and fish-borne zoonoses. Veterinary Parasitology 64: 143-147.

24. Ethiopian Central Statistical Agency (CSA) (2015) Annual Ethiopian Animal Population Estimates.

25. Thrusfield M (2005) Veterinary Epidemiology. ( $2^{\text {nd }}$ edn), Black Well Science tropics, Exford, UK.

26. Gracey F, Collins Ds, Hiley J (2009) Meat hygine (10 th $^{\text {th }}$ edn), Harcort Brace and Company. London, UK, pp. 400-401.

27. Tolosa T, Tigre W, Teka G, Dorny P (2009) Prevalence of bovine cysticercosis and hydatidosis in Jimma municipal abattoir, South West Ethiopia. Onderstepoort Journal of Veterinary Research. 76: 323-326.

28. Gomol T, Achnef M, Basazenuw B, Mersha C (2011) Cyst Viability, Body Site Distribution and Public Health Significance of Bovine Cysticercosis at Jimma, South West Ethiopia. Global Veterinarian.7(2): 164-168.

29. Ibrahim N, Zerihun F (2012) Prevalence of Tania Saginata Cysticercosis in Cattle Slaughtered in Addis Ababa Municipal Abattoir, Ethiopia. Global Veterinarian, 8: 467-471.

30. Regassa A, Abunna F, Mulugeta A, Megersa B (2009) Major metacestodes in cattle slaughtered at Wolaita Soddo Municipal abattoir Southern Ethiopia: Prevalence, cyst viability, organ distribution and socioeconomic implications. TropicalAnimal Health and Production.41: 1495-1502.

31. Kebede N, Tilahun G, Hailu A (2009) Current Status of Bovine 
Cysticercosis of Slaughtered Cattle in Addis Ababa Abattoir, Ethiopia. Tropical Animal Health and Production 41: 291-294.

32. Wanzala W, Onyango A, Kang K, Zessin H, Kyule M (2003) Control of Taenia Saginata by post-mortem examination of carcasses. African Health Science 3: 68-76.

33. Abunna F, Tilahun G, Megersa B, Regassa A (2007) Taeniasis and Its Socio-Economic Implication in Hawassa Town and Its Surroundings, Southern Ethiopia. East African Journal of Public Health, 4(2): 73-79.

34. Jemal E, Haileleul N (2011) Bovine cysticercosis: Prevalence, Cyst viability and distribution in cattle slaughtered at Konbolcha Elfora,

This work is licensed under Creative Commons Attribution 4.0 License

DOI: $10.19080 / J D V S .2019 .09 .555754$
Meat factory, Ethiopia. American Eurasian Journal of Agriculture and Environmental Sciences, 11: 173-176.

35. Carlos E, Armando N, William A (2003) Taenia solium cysticercosis/ Taeniasis: Potential linkage with FAO activities; FAO support possibilities, Animal production And Health division, Animal health service FAO, Rome, Italy, 87(1): 145-148.

36. Leilt E, Dasalew T, Tsegabirhan K, Tashale S, Yohannes H (2011) Prevalence and public health significance of bovine cysticercosis at Elfora Abattoir, Bishoftu. Ethiopia. Journal of Public Health and Epidemiology 7(2): 36-40.

\begin{tabular}{l} 
Your next submission with Juniper Publishers \\
will reach you the below assets \\
- Quality Editorial service \\
- Swift Peer Review \\
- Reprints availability \\
- E-prints Service \\
- Manuscript Podcast for convenient understanding \\
- Global attainment for your research \\
- Manuscript accessibility in different formats \\
( Pdf, E-pub, Full Text, Audio) \\
- Unceasing customer service \\
Track the below URL for one-step submission \\
https://juniperpublishers.com/online-submission.php \\
\hline
\end{tabular}

